\title{
Heart transplantation with donors fifty years of age and older
}

\author{
Carlos Blanche, MD \\ Andreas Kamlot, MD \\ Dominique A. Blanche, ScB \\ Brenda Kearney, RN \\ Kathy E. Magliato, MD \\ Lawrence S. C. Czer, MD \\ Alfredo Trento, MD
}

From the Division of Cardiothoracic Surgery, Cedars-Sinai Medical Center, Los Angeles, Calif.

Received for publication May 4, 2001; revisions requested June 29, 2001; revisions received Aug 1, 2001; accepted for publication Aug 31, 2001.

Address for reprints: Carlos Blanche, MD, Division of Cardiothoracic Surgery, CedarsSinai Medical Center, 8700 Beverly Blvd, Suite 6215, Los Angeles, CA 90048 (E-mail: Carlos.Blanche@cshs.org).
J Thorac Cardiovasc Surg 2002;123:810-5

Copyright (C) 2002 by The American Association for Thoracic Surgery

0022-5223/2002 $\$ 35.00+0 \quad \mathbf{1 2 / 1 / 1 2 0 0 0 9}$

doi:10.1067/mtc.2002.120009
Objective: Limited availability of donor organs has led to the progressive expansion of the criteria for donor selection, particularly a higher age limit of potential donors. We retrospectively reviewed the outcomes of patients who underwent heart transplantation using cardiac allografts 50 years of age and older and compared them with patients who had donor organs younger than 50 years.

Method: Between September 1989 and May 2000, 20 patients underwent orthotopic heart transplantation using donor hearts 50 years of age and older (range 50-56 years, mean $52.7 \pm 1.8$ years) and were compared with 267 patients who received donor organs less than 50 years of age (range 9-49.9 years, mean $27.2 \pm 8.6$ years). Patient and donor criteria were identical in both groups. Follow-up was 4 to 128 months with a mean of $37.4 \pm 2.8$ months in the older donor group and $52.6 \pm 2.4$ months in the younger donor group.

Results: There were no differences between these 2 cohorts of patients regarding age, sex, cardiomyopathy, preoperative cytomegalovirus status, New York Heart Association class, and transplant status at transplantation. Donor characteristics, including sex, left ventricular ejection fraction, diabetes, cytomegalovirus status, and allograft ischemic times, were also similar in the 2 groups. Donor/recipient cytomegalovirus matching showed no differences as well. Thirty-day or to discharge operative mortality was similar in the older and younger donor groups $(5 \%$ $\pm 4.8 \%$ vs $3.5 \% \pm 1.1 \% ; P=.84)$. Actuarial survival at 1 and 5 years was also similar in both groups $(89.7 \% \pm 6.9 \%$ vs $91 \% \pm 1.8 \%$ and $53.1 \% \pm 14.7 \%$ vs $71.0 \% \pm$ $3.1 \%$, respectively; $P=.59$ ). No patient in the older donor group required coronary artery bypass grafting or retransplantation during the follow-up period, whereas 2 patients in the younger donor group required coronary artery bypass, and 5 patients underwent retransplantation $(P \geq .50)$. Two patients in the older donor group died of nonspecific allograft failure, whereas 3 patients in the younger donor group experienced similar posttransplant complication $(P \geq .50)$.

Conclusions: Carefully selected donor hearts 50 years of age and older can be used for heart transplantation with long-term survival and related outcomes similar to those of younger donor organs. This use of selective cardiac allografts maximizes donor organ usage and expands the donor pool effectively without an adverse impact on long-term results.

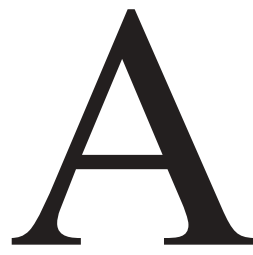

$\mathrm{s}$ the effectiveness of heart transplantation for the treatment of end-stage heart disease has long been proven, the pressure to meet the increasing demand for donor organs has led the transplant community to broaden and expand the criteria for donor acceptance. The use of high-risk cardiac allografts has been advocated to expand the donor pool and to meet the supply-demand mis- 
TABLE 1. Preoperative recipient characteristics

\begin{tabular}{|c|c|c|c|}
\hline & $\begin{array}{c}\text { Donor } \geq 50 \\
\text { years }(n=20)\end{array}$ & $\begin{array}{c}\text { Donor }<50 \\
\text { years }(n=267)\end{array}$ & $P$ value \\
\hline \multicolumn{4}{|c|}{ Age at transplant (y) } \\
\hline Mean \pm SD & $67.1 \pm 10.4$ & $56.4 \pm 11.1$ & $<.05$ \\
\hline Range & 41-74 & $14-77$ & \\
\hline \multicolumn{4}{|l|}{ Sex } \\
\hline Male & $16(80 \%)$ & $228(85 \%)$ & .52 \\
\hline Female & $4(20 \%)$ & $39(15 \%)$ & \\
\hline \multicolumn{4}{|l|}{ Cardiomyopathy } \\
\hline Ischemic & $13(65 \%)$ & $157(59 \%)$ & .16 \\
\hline Idiopathic & $6(30 \%)$ & $103(38.4 \%)$ & \\
\hline Congenital & $1(5 \%)$ & $-(0 \%)$ & \\
\hline Chagas disease & $-(0 \%)$ & $3(1 \%)$ & \\
\hline Other & $-(0 \%)$ & $4(1.6 \%)$ & \\
\hline \multicolumn{4}{|l|}{ CMV status } \\
\hline Positive & $17(85 \%)$ & $190(71 \%)$ & .14 \\
\hline Negative & $3(15 \%)$ & $77(29 \%)$ & \\
\hline \multicolumn{4}{|l|}{ NYHA class } \\
\hline II & $-(0 \%)$ & $17(6 \%)$ & .23 \\
\hline III & $10(50 \%)$ & $17(32 \%)$ & \\
\hline \multicolumn{4}{|c|}{ Transplant status (UNOS) } \\
\hline 1 & $8(40 \%)$ & $170(64 \%)$ & .05 \\
\hline 2 & $12(60 \%)$ & $97(36 \%)$ & \\
\hline \multicolumn{4}{|c|}{$\begin{array}{l}\text { Waiting time to } \\
\text { transplantation (mo) }\end{array}$} \\
\hline Mean \pm SD & $2.8 \pm 1.4$ & $3.8 \pm 1.9$ & $<.05$ \\
\hline Range & $1-9$ & $1-37$ & \\
\hline
\end{tabular}

CMV, Cytomegalovirus; NYHA, New York Heart Association; UNOS, United Network for Organ Sharing; $S D$, standard deviation.

match for patients awaiting heart transplantation. Although there is evidence from the Registry of the International Society of Heart and Lung Transplantation (ISHLT) that older donors have an adverse prognosis, ${ }^{1}$ other reports indicate that advanced donor age is not necessarily associated with poor results and would seem a viable option for selected patients. ${ }^{2-6}$ To assess the effect of increased donor age on final outcome, we retrospectively analyzed the results of 20 patients who underwent heart transplantation using cardiac allografts 50 years of age and older over an 11-year period. We then compared these results with those of 267 patients who received donor organs less than 50 years of age over the same period, using identical immunosuppression and cytomegalovirus (CMV) prophylaxis protocols.

\section{Patients and Methods}

Between September 1989 and May 2000, 287 patients underwent heart transplantation at Cedars-Sinai Medical Center. Of those, 20 patients received donor organs 50 years of age and older (range 50-56 years, mean $52.7 \pm 1.8$ years), whereas the remaining 267
TABLE 2. Donor heart and intraoperative characteristics

\begin{tabular}{|c|c|c|c|}
\hline & $\begin{array}{c}\text { Donor } \geq 50 \\
\text { years }(n=20)\end{array}$ & $\begin{array}{c}\text { Donor }<50 \\
\text { years }(n=267)\end{array}$ & $P$ value \\
\hline \multicolumn{4}{|l|}{ Age (y) } \\
\hline Mean \pm SD & $52.7 \pm 1.8$ & $27.2 \pm 8.6$ & $<.05$ \\
\hline Range & $50-56$ & $9-49.9$ & \\
\hline \multicolumn{4}{|l|}{ Sex } \\
\hline Male & $16(80 \%)$ & $194(73 \%)$ & .61 \\
\hline Female & $4(20 \%)$ & $73(27 \%)$ & \\
\hline \multicolumn{4}{|l|}{ LVEF } \\
\hline$\geq 50 \%$ & $18(90 \%)$ & $247(93 \%)$ & .66 \\
\hline $40-50 \%$ & $2(10 \%)$ & $20(7 \%)$ & \\
\hline Diabetes mellitus & $1(5 \%)$ & $2(1 \%)$ & \\
\hline Pretransplant angiogram & $\mathrm{n}=13$ & $\mathrm{n}=16$ & $\mathrm{~N} / \mathrm{A}$ \\
\hline Abnormal angiogram (CAD) & $4(31 \%)$ & $2(13 \%)$ & \\
\hline \multicolumn{4}{|l|}{ Allograft ischemic time (min) } \\
\hline Mean \pm SD & $163 \pm 36.8$ & $161 \pm 17.0$ & .50 \\
\hline Range & $65-250$ & $60-327$ & \\
\hline Associated surgery (CABG) & $1(5 \%)$ & $2(0.7 \%)$ & \\
\hline \multicolumn{4}{|l|}{ Allograft CMV status } \\
\hline Positive & $11(55 \%)$ & $167(62 \%)$ & .63 \\
\hline Negative & $9(45 \%)$ & $100(38 \%)$ & \\
\hline \multicolumn{4}{|l|}{$\begin{array}{l}\text { Donor/recipient CMV } \\
\text { matching }\end{array}$} \\
\hline $\mathrm{D}+/ \mathrm{R}+$ & $9(45 \%)$ & $116(43 \%)$ & .62 \\
\hline $\mathrm{D}+/ \mathrm{R}-$ & $2(10 \%)$ & $51(19 \%)$ & \\
\hline $\mathrm{D}-/ \mathrm{R}_{+}$ & $8(40 \%)$ & $74(28 \%)$ & \\
\hline $\mathrm{D}-/ \mathrm{R}-$ & $1(5 \%)$ & $26(10 \%)$ & \\
\hline
\end{tabular}

$\angle V E F$, Left ventricular ejection fraction; $C A D$, coronary artery disease; $C A B G$, coronary artery bypass grafting; $C M V$, cytomegalovirus; $S D$, standard deviation.

patients received cardiac allografts younger than 50 years of age (range 9-49.9 years, mean 27.2 \pm 8.6 years). Cardiac allografts 50 years of age and older were allocated preferentially to recipients 50 years of age and older unless there was a younger patient with an urgent need for a donor heart. The United Network for Organ Sharing (UNOS) and the specific organ procurement agency established the guidelines for donor organ allocation (eg, priority status and time accrued in the waiting list, taking into consideration the recipient's blood type, weight, sex, pulmonary vascular resistance, and transpulmonary gradient, among others). The mean age of those status 1 transplant patients with donor organs 50 years of age and older was 58.3 \pm 11.0 years (range 41-69 years), whereas it was $64.0 \pm 9.7$ years (range $42-74$ years) for those patients waiting as status 2 . The preoperative patient characteristics are shown in Table 1 . Since all recipients were listed for transplantation by the same selection criteria, the potential differences in the myocardial oxygen consumption values, pulmonary artery pressures, pulmonary vascular resistance, transpulmonary gradients, or the number of previous cardiac operations between the older and the younger donor patient groups were thought to be nonsignificant and, thus, not analyzed separately. Donor heart and intraoperative characteristics are presented in Table 2. Our criteria to evaluate potential donors were identical in both groups, and a 


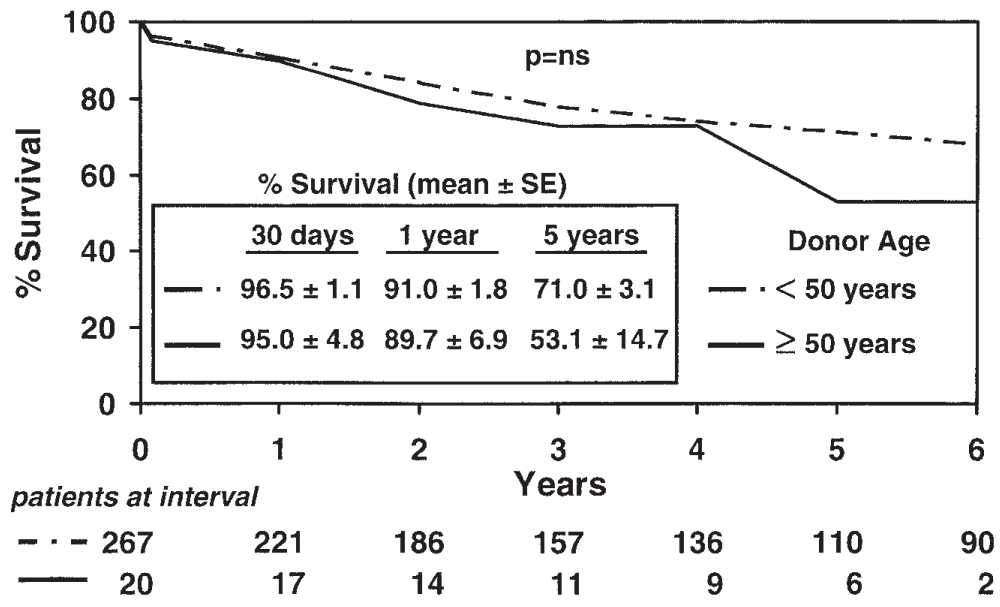

Figure 1. Thirty-day operative survival and actuarial survival up to 5 years for both donor age groups. ns, Not significant; $S E$, standard error.

preoperative coronary angiogram was requested for donors 40 years of age and older or for donor hearts with segmental wall motion abnormalities seen on echocardiography. However, a preoperative coronary angiogram or echocardiogram was not always available at the donor hospital. Thus, in the absence of these tests, the decision was made by the harvesting surgeon on the basis of visual inspection and examination of the donor heart. Those patients who received a cardiac allograft older than 40 years of age without a preoperative coronary angiogram or echocardiogram underwent these studies before discharge from the hospital. Follow-up was 4 to 128 months with a mean of $37.4 \pm 2.8$ months in the older donor group and $52.6 \pm 2.4$ months in the younger donor group.

For the statistical analysis, continuous variables were analyzed with the use of a 2-sample $t$ test to compare differences between the 2 donor groups. Categorical variables were analyzed by the Fisher exact test.

\section{Immunosuppressive Therapy}

Immunosuppressive therapy consisted of OKT3 induction therapy (5 mg intravenously daily) for 7 days. However, patients with impaired renal function (serum creatinine $>2.5 \mathrm{mg} / \mathrm{dL}$ ) or patients undergoing combined heart-kidney transplantation received antithymocyte globulin (ATG) (15 mg/kg daily, adjusted for white blood cell count and platelet count) for 7 days. Maintenance immunosuppressive therapy consisted of cyclosporine (INN: ciclosporin) (5 mg/kg per day, for a level of 200 to $400 \mathrm{ng} / \mathrm{mL}$, as measured by a monoclonal fluorescence polarization immunoassay, within the first 12 weeks after transplantation, and a level of 120 to $200 \mathrm{ng} / \mathrm{mL}$ thereafter, started postoperatively once the serum creatinine was less than $2.0 \mathrm{mg} / \mathrm{dL})$; azathioprine $(4 \mathrm{mg} / \mathrm{kg}$ preoperatively, and $2 \mathrm{mg} / \mathrm{kg}$ per day postoperatively, adjusted to the patient's white blood cell count and platelet count), but switched to mycophenolate mofetil (1000 mg twice daily) for all patients as of January 1997 (includes 7 patients in the older donor group and 73 patients in the younger donor group); and steroids (methylprednisolone sodium succinate, $1 \mathrm{mg}$ at removal of the aortic crossclamp intraoperatively, and then $125 \mathrm{mg}$ intravenously every 8 hours for 3 doses postoperatively, followed by prednisone, $0.25 \mathrm{mg} / \mathrm{kg}$ per day during OKT3 or ATG therapy, increased to 0.5 $\mathrm{mg} / \mathrm{kg}$ per day, and then tapered off in the subsequent 3 to 8 months). Endomyocardial biopsies were performed according to our surveillance protocol or when acute cardiac rejection was clinically suspected. Cardiac rejection episodes were treated if greater than 1 B (International Society for Heart and Lung Transplantation classification). Routine 2-dimensional echocardiograms and coronary angiograms were performed at yearly intervals or more frequently when clinically indicated.

\section{Cytomegalovirus Prophylaxis}

Most patients were given 6 doses of intravenous immunoglobulin $(500 \mathrm{mg} / \mathrm{kg})$ within 1 week after transplantation, with 5 doses of intravenous cytomegalovirus (CMV) specific immune globulin $(125 \mathrm{mg} / \mathrm{kg})$ after the first intravenous immunoglobulin dose. Intravenous ganciclovir was also administered (5 mg/kg every 12 hours but adjusted for renal function) for 14 weeks followed by oral ganciclovir (1000 mg twice daily but adjusted for renal function) for an additional 38 weeks for those patients who were donor CMV positive/recipient CMV negative (high risk). For those patients donor CMV positive/recipient CMV positive and for those donor CMV negative/recipient CMV positive (low risk), prophylaxis consisted of 6 doses of intravenous immunoglobulin and intravenous ganciclovir for 2 weeks followed by oral acyclovir (3200 mg daily but adjusted for renal function) for 24 weeks. Prophylaxis for high-risk patients spanned the first posttransplantation year, whereas CMV prophylaxis for low-risk patients lasted the first 6 months after transplantation.

\section{Results}

The 30-day or to discharge operative mortality was similar in the older and the younger donor groups $(5 \% \pm 4.8 \%$ vs 
TABLE 3. Postoperative CMV infection and allograft rejection

\begin{tabular}{lccc}
\hline & Donor $\geq \mathbf{5 0}$ y & Donor $<\mathbf{5 0}$ y & P value \\
\hline CMV infection & $2(10 \%)$ & $12(4.5 \%)$ & .26 \\
Rejection $\geq 1 B^{*}$ & $4(20 \%)$ & $106(40 \%)$ & .09 \\
\hline
\end{tabular}

CMV, Cytomegalovirus.

*International Society for Heart and Lung Transplantation classification.

$3.5 \% \pm 1.1 \%, P=.84)$. Actuarial survival at 1 and 5 years also was similar in both groups $(89.7 \% \pm 6.9 \%$ vs $91 \% \pm$ $1.8 \%$ and $53.1 \% \pm 14.7 \%$ vs $71.0 \% \pm 3.1 \%$, respectively, $P$ $=.59$ ) (Figure 1). One patient in the older donor group and 2 patients in the younger donor group required concomitant coronary artery bypass grafting (CABG) at the time of transplantation and are alive and well at 24, 12, and 75 months, respectively. The incidences of posttransplant CMV infection and allograft rejection (>1 B) were also similar and are shown in Table 3. Insufficient data preclude comparison of posttransplant incidence of percutaneous transluminal coronary angioplasty/stent interventions in both groups. No patients in the older donor group required CABG for significant allograft coronary artery disease (CAD) or retransplantation for allograft vasculopathy or nonspecific graft dysfunction during the follow-up period. Two patients in the younger donor group required CABG (at 25 and 36 months, respectively), and an additional 5 patients required retransplantation (at 1, 19, 43, 48, and 73 months, respectively) $(P \geq .50)$. The mean posttransplant left ventricular ejection fraction in the older donor group was $56.5 \% \pm 13.4 \%$ (range $45 \%-72 \%$ ), but a statistically significant comparison with the younger donor group could not be made because of insufficient data in the latter group. Two patients in the older donor group died of nonspecific allograft failure in the late follow-up period (at 18 and 27 months, respectively), whereas 3 patients in the younger donor group had similar posttransplant complication (at 13, 21 , and 42 months, respectively) $(P \geq .50)$. Their postmortem diagnosis was confirmed in all patients by autopsy. The causes of death are shown in Table 4.

\section{Discussion}

The use of donor hearts from high-risk donors has allowed for the expansion of the donor pool and increased organ recovery rates of $20 \%$ to $30 \%$ annually. ${ }^{7}$ However, the use of these high-risk cardiac allografts should be very selective, and the potential benefits should far outweigh the risks. This is particularly true for older donors, although there is no consensus on what constitutes an older donor. Donor age has traditionally been considered a risk factor for the development of CAD in the transplanted allograft with subsequent
TABLE 4. Cause of death

\begin{tabular}{lcc}
\hline & $\begin{array}{c}\text { Donor } \geq \mathbf{5 0} y \\
(\mathbf{n}=\mathbf{7})\end{array}$ & $\begin{array}{c}\text { Donor }<\mathbf{5 0} \mathbf{y} \\
(\mathbf{n}=\mathbf{7 1})\end{array}$ \\
\hline Allograft atherosclerosis & 2 & 23 \\
Nonspecific graft failure & 2 & 3 \\
Sepsis & 1 & 11 \\
Cancer & - & 17 \\
Renal failure & - & 4 \\
Acute right ventricular failure & - & 2 \\
Mediastinal hemorrhage & - & 2 \\
Acute rejection & 1 & 1 \\
Sudden death & 1 & - \\
Other & - & 8 \\
\hline
\end{tabular}

increased morbidity and mortality and allograft vasculopathy. ${ }^{1,8-10}$ Further, an analysis of the UNOS database showed that older donors have a significant increase in early postoperative mortality and 1-year mortality that persists at the 5year point. Advanced donor age is known to be a strong adverse predictor of mortality second only to retransplantation. ${ }^{11}$ In addition, there is a statistically significant interaction between allograft ischemic time and donor age that affects short- and long-term survival. ${ }^{1}$ In a study by Loebe and colleagues, ${ }^{2}$ the incidence of posttransplant cardiac events was much lower when younger donors were used. It included a lower rate of percutaneous transluminal coronary angioplasty, $\mathrm{CABG}$, and retransplantation with donor hearts less than 35 years of age compared with donor hearts 35 to 50 years and those older than 50 years of age. ${ }^{2}$

However, some of these unfavorable results may be due to the fact that older donor hearts traditionally have been allocated to older recipients or high-risk patients and even used as a "biologic bridge" to transplantation until a younger allograft could be available. ${ }^{2,6,12}$ Data from the Registry of the ISHLT ${ }^{1}$ show that advanced recipient age is another strong factor that adversely affects survival, which may further compound the increased mortality associated with older donors. With the ever-expanding heart transplant recipient population, new strategies for increasing the donor pool have been pursued and the lack of the "ideal" donor heart has expanded the criteria for acceptance of potential donors. Older donor hearts with negative cardiac history and serologies, normal electrocardiogram and echocardiogram, low inotropic support, normal coronary angiogram, and an expected short ischemic time may fill this void. In a study by Ibrahim and colleagues, ${ }^{5}$ extended ischemic time ( $>240$ minutes, mean $255.8 \pm 6.9$ minutes) and increased donor age ( $>40$ years, mean $46.4 \pm 0.8$ years) did not adversely affect early survival after heart transplantation although no long-term survival was reported. Although some series have reported satisfactory intermediate and 
long-term results after heart transplantation with the use of older donors, $2,3,6,8,12-14$ there are studies that suggest that the extension of the donor age predisposes the recipient to allograft vasculopathy. ${ }^{2,8}$

The role of CMV infection has been postulated to accelerate the development of allograft vasculopathy in older cardiac allografts although the exact mechanism is not clearly known. ${ }^{15}$ As older individuals, and thus potential donors, tend to have a higher percentage of CMV seropositivity, this may adversely affect the development of CMV disease in recipients with older allografts. ${ }^{16}$ Our experience as well as others ${ }^{2}$ indicates no significant difference in the incidence of postoperative CMV infection or allograft rejection.

Some investigators advocate the use of selective, rather than routine, coronary angiography to evaluate the presence of CAD in the older donor heart. ${ }^{2,4}$ As invasive preoperative studies are not always available at the donor hospital, these potential cardiac allografts should be carefully examined by visual inspection and palpation of the coronary arteries, although the sensitivity and specificity of such techniques are limited. In our experience, coronary arteriography was available in $65 \%$ of our older donor population. In the remaining 7 patients, this study was performed before discharge and failed to show any significantly obstructive coronary artery lesion in all of them. Although it appears that there is an increased incidence of CAD requiring posttransplant $\mathrm{CABG}$ and retransplantation in the younger-age donor group, along with a longer mean follow-up time, it did not achieve statistical significance. Only long-term follow-up of these 2 groups of heart transplant recipients involving large numbers of patients will accurately determine the true incidence of significant CAD in each cohort of patients. Thus, it may influence the use of older donors for heart transplantation. However, Chau and colleagues ${ }^{6}$ reported a much greater incidence of chronotropic incompetence requiring placement of a permanent pacemaker in patients with older donor hearts that was independent of allograft ischemic time and pretransplantation amiodarone therapy. This seems to be a technical rather than a physiologic or an age-related event. We have completely abolished the need for a permanent pacemaker because of sinus node dysfunction in the early posttransplant period in our last 236 consecutive patients undergoing heart transplantation. This was accomplished by adopting an alternative technique for implantation of the cardiac allograft consisting of bicaval and pulmonary venous anastomoses as our standard technique, including all the patients reported in this study. ${ }^{17}$ Further, even though there was a slight modification in the immunosuppressive protocol for all patients in the last 3 years of this study, it had no direct impact on the survivals in either group.

Although there are some limitations and methodologic restrictions of this study-such as the small number of patients involved in the older donor group and the insufficient data regarding posttransplant angioplasty/stent interventions (usually performed at the referring hospital)_some valid conclusions can be drawn. On the basis of our experience with older donor hearts, we believe that donor age per se should not be a contraindication for consideration for heart transplantation. These older donor hearts should be accepted regardless of age, provided they demonstrate satisfactory physiologic and hemodynamic performance. In fact, our allocation criteria for cardiac allografts 50 years of age and older have evolved since the completion of this study; those donor organs are now matched with the proper recipient on the basis of the clinical characteristics of the donor and recipient, regardless of the recipient's age. Exception is made in those rare circumstances of donor organs with documented limited CAD that require concomitant $\mathrm{CABG}$ at the time of allograft implantation; those cardiac allografts are usually matched with recipients 60 years of age and older who are in urgent need of transplantation. The selective use of older allografts for heart transplantation maximizes organ use and would expand the donor pool without an adverse effect on long-term results. This approach implies a careful selection and close surveillance for the development of allograft vasculopathy. Further, even the use of the "less than ideal" older donor heart should be considered and assessed on a case-by-case basis. Such is the case when mild to moderate CAD is present or a more prolonged period of allograft ischemic time would be expected, provided it is selectively allocated to the proper recipient. An exception to these expanded criteria is the use of hepatitis C-positive donors, even in hepatitis $\mathrm{C}$ positive recipients since there is more than one strain of the virus and the presence of antiviral antibody does not guarantee immediate immunity. ${ }^{18}$ Experience with kidney transplantation $^{19}$ indicates that nearly all recipients from hepatitis $\mathrm{C}$-positive donors become infected with the virus. There is no reason to believe that hepatitis $\mathrm{C}$-positive or hepatitis B-positive cardiac allografts would behave any differently.

Finally, with the exponential expansion of heart transplant recipient lists and the limited donor organ availability, the use of the less than ideal cardiac allograft has become a necessity and is no longer an isolated event. There is an accepted attitude to "bend the rules" and expand these criteria for the urgent transplant recipient with otherwise no possibility for survival. An older donor heart has traditionally represented a high-risk donor, but the clinical and ethical dilemma has been partially answered by the satisfactory long-term results achieved with the use of other "unacceptable" heart donors in younger and not so critically ill patients. ${ }^{12}$ The objective of applying selection criteria to organ donors is to provide recipients with the optimum chance for a successful transplantation, and our study may 
help clarify this issue. When faced with a critically ill patient awaiting transplantation, we believe an available donor heart represents a viable alternative to mechanical assist devices (with their attendant inherent morbidity and mortality). Does an older cardiac allograft (defined as 50 years of age and older), with normal anatomic and physiologic function, represent a higher risk alternative then a mechanical ventricular assist device? Although the comparison of survivals of such alternatives is not clearly known, the reluctance of many transplant centers to use older donor organs for heart transplantation must be balanced against the disparity that exists between supply and demand of donor organs. Unfortunately, this gap continues to grow and such devices will not alleviate the exponentially growing demand for donor organs.

Is the use of older donor hearts for transplantation only acceptable to older recipients, in whom the feasibility of a mechanical assist device may be limited or perhaps contraindicated, or is it equally applicable to younger recipients awaiting heart transplantation in a more elective fashion? Many facets of this study warrant further investigation to answer the many questions raised, but the satisfactory results with this group of older donor hearts may expand the acceptance criteria even further in the future. In addition, it is fundamentally important to recognize patients' preferences regarding the different alternatives available, particularly for the younger and the not so urgent patients waiting for transplantation, to reconcile the practical, clinical, and moral issues involved.

A careful follow-up and continued analysis of these data from larger series and/or multicenter studies may define the true risks and benefits of this approach and may guide the limits of expanding the donor criteria.

\section{References}

1. Hosenpud JD, Bennett LE, Keck BM, Fiol B, Boucek MM, Novick RJ. The Registry of the International Society for Heart and Lung Transplantation: sixteenth official report-1999. J Heart Lung Transplant. 1999;18:611-26.
2. Loebe M, Potapov EV, Hummel M, Weng Y, Bocksch W, Hetzer R. Medium-term results of heart transplantation using older donor organs. J Heart Lung Transplant. 2000;19:957-63.

3. Jacobbi LM, McBride V, Like K, Rose D. Increasing the donor pool: recovery of hearts from older donors. Transplant Proc. 1997;29: 3297-8.

4. Pflugfelder PW, Singh NR, McKenzie FN, Menkis AH, Novick RJ, Kostuk WJ. Extending cardiac allograft ischemic time and donor age: effect on survival and long-term cardiac function. J Heart Lung Transplant. 1991;10:394-400.

5. Ibrahim M, Masters RG, Hendry PJ, et al. Determinants of hospital survival after cardiac transplantation. Ann Thorac Surg. 1995;59:604-8.

6. Chau EMC, McGregor CGA, Rodeheffer RJ, et al. Increased incidence of chronotropic incompetence in older donor hearts. $J$ Heart Lung Transplant. 1995;14:743-8.

7. Jacobbi LM, McBride VA, Etheredge EE, et al. The risks, benefits, and costs of expanding donor criteria. Transplantation. 1995;60:1491-6.

8. Mercer P, Sharples L, Edmunds J, et al. Evaluating the donor pool: impact of using hearts from donors over the age of 49 years. Transplant Proc. 1997;29:3293-6.

9. El Oakley RM, Yonan NA, Simpson BM, Deiraniya AK. Extended criteria for cardiac allograft donors: a consensus study. J Heart Lung Transplant. 1996;15:255-9.

10. Anyanwu AC, Rogers CA, Murday AJ. Should recipient risk be a factor in choosing recipients for suboptimal donor hearts? A multi-institutional study. Transplant Proc. 1999;31:1399-400.

11. Breen TJ, Keck B, Daly OP, Hosenpud JD. The use of older donors results in a major increase in early mortality following orthotopic heart transplantation [abstract]. J Heart Lung Transplant. 1994;13: S51.

12. Menkis AH, Novick RJ, Kostuk, et al. Successful use of the "unacceptable" heart donor. J Heart Lung Transplant. 1991;10:28-32.

13. Mulvagh SL, Thorton B, Frazier H, et al. The older cardiac transplant donor: relation to graft function and recipient survival longer than 6 years. Circulation. 1989;80(Suppl):III-126-32.

14. Schuler S, Warnecke W, Loebe M, Fleck E, Hetzer R. Extended donor age in cardiac transplantation. Circulation. 1989;80(Suppl):III-133-9.

15. Loebe M, Schuler S, Zais O, Warnecke W, Fleck E, Hetzer R. Role of cytomegalovirus infection in the development of coronary artery disease in the transplanted heart. J Heart Transplant. 1990;9:707-11.

16. Weymouth L, Gomolin I, Brennan T, Sirpenski S, Mayo D. Cytomegalovirus antibody in the elderly. Intervirology. 1990;31: 223-9.

17. Blanche C, Nessim S, Quartel A, et al. Heart transplantation with bicaval and pulmonary venous anastomoses: a hemodynamic analysis of the first 117 patients. J Cardiovasc Surg. 1997;38:561-6.

18. Pereira BJ, Milford EL, Kirkman RL, et al. Prevalence of hepatitis C virus in organ donors positive for hepatitis $\mathrm{C}$ antibody and in recipients of their organs. N Engl J Med. 1992;327:910-5.

19. Pereira BJ, Milford EL, Kirkman RL, Levey AS. Transmission of hepatitis C virus by organ transplantation. N Engl J Med. 1991; $325: 454-60$. 